\title{
Assessment of electrocardiogram abnormality and associated factors among apparently healthy adult type 2 diabetic patients on follow-up at Jimma Medical Center, Southwest Ethiopia: Cross-sectional study
}

Deriba A. Bedane ${ }^{1 *} \mathbb{0}$, Samuel Tadesse ${ }^{1}$, Moyeta Bariso ${ }^{1}$, Wondu Reta ${ }^{1}$ and Gaddisa Desu ${ }^{2}$

\begin{abstract}
Background: Diabetes mellitus is a group of metabolic disorders causing long-term damage to the cardiovascular system which remains asymptomatic among diabetic patients. An electrocardiograph is a simple and first-line tool in the screening of cardiovascular diseases.

Objective: To assess electrocardiogram abnormality and associated factors among apparently healthy adult type 2 diabetes patients on follow-up at Jimma Medical Center, 2019.

Materials and methods: Institutional based cross-sectional study was conducted from April 1 to May 30, 2019, at Jimma Medical Center among selected type 2 diabetes patients. Systematic random sampling was employed to select the study participants. The World Health Organization stepwise approach and interviewer-administered semistructured questionnaires were employed to collect basic data. Resting Electrocardiography was done using a standard 12-lead electrocardiograph machine. The collected data were checked for completeness, coded, entered into the Epi-data Version 4.0.2. and exported to SPSS Version 21. Descriptive statistics like frequencies, percentages, mean and standard deviations were carried out. Binary and multiple logistic regression was done and a $p$ value of less than 0.05 was used as a level of significance.
\end{abstract}

Results: A total of 344 type 2 diabetes patients were interviewed and underwent electrocardiography making a 100\% response rate. Electrocardiographic abnormality was identified among 209 (61\%) of the respondents. Not attending formal education $[\mathrm{AOR}=3.07,95 \%, \mathrm{Cl}=1.37-6.87]$, solid oil use, $[\mathrm{AOR}=1.79,95 \%, \mathrm{Cl}=1.07-2.98]$, body mass index $\geq 25 \mathrm{~kg} / \mathrm{m}^{2}[\mathrm{AOR}=2.74,95 \%, \mathrm{Cl}=1.67-4.50]$ and long duration of diabetes $\geq 10$ years $[\mathrm{AOR}=3.36,95 \%$, $\mathrm{Cl}=1.46-7.71]$ were associated with electrocardiogram abnormality.

Conclusions: and recommendation

In this study, the majority (3/5th) of the participant had electrocardiogram abnormality. Not attending formal education, longer duration of diabetes $\geq 10$ years, solid oil use, and increased body mass index $\geq 25 \mathrm{~kg} / \mathrm{m}^{2}$ were

\footnotetext{
*Correspondence: deribaabera@gmail.com; diriba.bedane@ju.edu.et

${ }^{1}$ Department of Biomedical Sciences, Physiology Unit, College of Medical

Sciences, Institute of Health, Jimma University, Jimma, Ethiopia

Full list of author information is available at the end of the article
}

(C) The Author(s) 2021. Open Access This article is licensed under a Creative Commons Attribution 4.0 International License, which permits use, sharing, adaptation, distribution and reproduction in any medium or format, as long as you give appropriate credit to the original author(s) and the source, provide a link to the Creative Commons licence, and indicate if changes were made. The images or other third party material in this article are included in the article's Creative Commons licence, unless indicated otherwise in a credit line to the material. If material is not included in the article's Creative Commons licence and your intended use is not permitted by statutory regulation or exceeds the permitted use, you will need to obtain permission directly from the copyright holder. To view a copy of this licence, visit http://creativecommons.org/licenses/by/4.0/. The Creative Commons Public Domain Dedication waiver (http://creativeco mmons.org/publicdomain/zero/1.0/) applies to the data made available in this article, unless otherwise stated in a credit line to the data. 
independent predictors of electrocardiographic abnormality. Integrating electrocardiogram screening in routine diabetic management can pick cardiac complications of diabetes.

Keywords: Type 2 diabetes mellitus, ECG abnormality, Minnesota ECG criteria, Jimma medical center

\section{Background}

Diabetes mellitus (DM) is a group of metabolic disorders characterized by chronic hyperglycemia due to defects in insulin secretion, action, or both which leads to metabolic disturbances [1]. Type 2 diabetes mellitus (T2DM) is caused by a progressive loss of $\beta$-cell insulin secretion on the background of insulin resistance [2].

Diabetes mellitus is growing globally at a rapid rate especially in middle and low-income countries like SubSahara aggravated by a change in socio-economic, nutritional, and lifestyles [3]. There were about 451 million diabetic adults between 18-99 years in 2017 making the global adult prevalence of $8.8 \%$. The adult prevalence of diabetes was $4.2 \%$ in Africa and $5.2 \%$ in Ethiopia in 2015 [4]. Currently, an epidemic of T2DM is increasing worldwide with $80 \%$ of them are living in low to middle-income countries [5]. In Africa, T2DM accounts for about $90-95 \%$ of all diabetes [6]. About $49.7 \%$ of the world and $69.2 \%$ of Africa's diabetes remained undiagnosed [7]. T2DM may present with or without symptoms and might cause long-term damage to the cardiovascular system [8].

Diabetes and CVDs account for more than $80 \%$ of deaths in developing countries [9]. The leading causes of morbidity and mortality among T2DM are atherosclerotic cardiovascular diseases such as coronary heart disease, cerebrovascular disease, or peripheral arterial disease [5]. There were about 3.7 million deaths due to hyperglycemia in 2012 worldwide. From these, 1.5 million deaths due to DM while 2.2 million CVDs deaths [10]. CVDs were the 2nd while diabetes was the 9th leading cause of premature death and disability in Ethiopia [11].

A link between DM and cardiovascular diseases (CVDs) is a central cause of morbidity and mortality in diabetic patients [12]. The relationship between diabetes and CVDs is complex and multifactorial including autonomic dysfunction, atrial and ventricular remodeling, and molecular alterations [13]. Additionally, dysglycemia, dyslipidemia, and hyperinsulinemia change metabolic profiles and cellular signaling of the cardiovascular system [14]. These all increase the risks of CVDs among diabetic populations. American heart association states CVDs risks increased 2- 4 times among T2DM [15].

Electrocardiogram (ECG) is the recording of cardiac electrical activity which provides the duration and amount of electrical activity of heart muscles [16]. A resting 12-lead electrocardiogram is frequently used in evaluating patients with suspected cardiovascular disease [17]. Usually, physicians do not routinely screen diabetic patients for arteriosclerotic unless the disease is suspected [18]. The presence of major ECG abnormality is associated with an increased risk of CVDs in diabetic patients [19]. To our knowledge, there is no study conducted in Ethiopia to assess the ECG abnormality and associated factors among an asymptomatic diabetic patient. Implementing an efficient noninvasive screening and identification of cardiac abnormalities can pick unrecognized and asymptomatic diabetic cardiac impairment [20]. Thus, this study is aimed to assess electrocardiogram abnormality and associated factors among apparently healthy adult T2DM patients.

\section{Methods}

\section{Study design and setting}

An Institutional based cross-sectional study was conducted from April, 1 to May 30, 2019, at Jimma Medical Center (JMC) which is located in Oromia Regional State, $350 \mathrm{~km}$ southwest of Addis Ababa. JMC is the referral teaching hospital giving health services to about 15 million people in the South West of Ethiopia. Diabetic patients getting follow-up service in the diabetic clinic are usually appointed in one to two months regularly.

\section{Study population and eligibility}

All adult type 2 diabetic patients who were on follow-up at diabetic clinics at JMC were a source population. The study population was all randomly selected adult type 2 diabetic patients on follow-up at JMC during the study period and who fulfill the eligibility criteria. All type 2 diabetic patients aged 18 years and above, who had no prior diagnosis of cardiovascular diseases were included in this study. Type 2 diabetic patients who were mentally impaired and unable to give information, or had diagnosed CVDs before the onset of diabetes mellitus were excluded. Type 2 diabetic patients with concomitant diseases like chronic liver disease, kidney disease, thyroid diseases, etc., as well as type 2 diabetic with acute complications diabetes ketoacidosis, or hyperosmolar hyperglycemic state, were also excluded.

\section{Sample size and sampling procedure}

The sample size was determined using a single population proportion formula by considering the following 
assumptions: $p=50 \%$ since no similar study done in Ethiopia, the margin of error $=5 \%$ and $95 \%$ confidence level $n=\frac{\left(z^{\alpha} / 2\right)^{2} p(1-p)}{d^{2}}=\frac{(1.96)^{2} \times 0.5 \times 0.5}{(0.05)^{2}}=384$. From chronic follow-up record data, the total number of type 2 diabetic patients on follow-up at JMC in 2018 was 1685 . Since the source population is less than 10,000 applying the formula for finite population correction the final sample size was calculated as follows.

$$
\begin{aligned}
& \quad n f=\frac{n}{\{1+(n / N\}}=\frac{384}{\{1+(384 / 1685)\}}=313 \text {. Adding } 10 \% \text { non- } \\
& \text { response rate }=313+31=344 \text {. }
\end{aligned}
$$

\section{Data collection tools and procedure}

World health organization (WHO) stepwise approach was employed for collecting the risks of CVDs among type 2 diabetic patients during entry [21]. The questionnaire was translated from English to Afan Oromo and back to English to assure its consistency in a blinded manner. A pre-test was done on $5 \%$ of the total sample size at Shanan Gibe Hospital before the actual data collection to ensure clarity, understandability, and completeness. Correction and modification on grammar, sequences, and timing were made based on the result of the pre-test before the start of actual data collection. Finally, the Afan Oromo version was used to collect data. Data collection was conducted through a face-to-face interview by trained data collectors using semi-structured questionnaires. The information related to the medical condition was reviewed from patients' medical charts. The questionnaires were checked for completeness by supervisors and principal investigators every day.

\section{Study variables}

The dependent variable of the study was ECG abnormality. The independent variables were sociodemographic factors (age, sex, educational status, occupation, and place of residence), factors related to a medical condition (duration of treatment and glycemic control), behavioral factors (physical activity, alcohol, tobacco, and khat use), nutritional factors (the type of cooking oil and fruit and vegetable intake), and factors related with body composition (weight, height, body mass index (BMI), waist circumference (WC), blood pressure (BP), and waist to hip ratio (WHR)).

\section{Operational definition}

Electrocardiography Recording the heart's electrical echoes using the ECG machine by placing electrodes on the surface of the body.

Normal sinus rhythm A regular heart rate between 50 and 100 beats per minute [22] with normal p waves, PR interval, QRS complex, $\mathrm{T}$ waves, and $\mathrm{p}$ waves preceding each QRS complex.
ECG abnormality Any ECG change beyond normal sinus rhythm (ST-segment elevation or depression, Twave aberrations (inversion or tall T-wave), AV nodal block, bundle branch block, chamber enlargement, and dilatation, ventricular hypertrophy, arrhythmias, and prolonged QT intervals).

Solid oil The palm oil which is solid at room temperature.

\section{Measurements}

The measurements of blood pressure, anthropometry (weight, height, waist circumference, and hip circumferences), fasting blood glucose level, and recording of electrocardiography were made according to the respective guidelines. Accordingly, the measurements of anthropometry were measured according to $\mathrm{WHO}$ guidelines [23] while BP was measured according to the European society of hypertension recommendation [24]. Fasting blood sugar (FBS) was measured according to Standard Operating Procedures Clinical and Translational Research Center [25] and ECG was recorded according to the standard manual for the Minnesota ECG criteria [22]. The height was measured to the nearest $0.5 \mathrm{~cm}$ with a stadiometer (Prestige Tokyo, Japan) as participants stand vertical with no shoes or headwear with their back against the stadiometer, heels together and eyes focused forward. The weight was measured to the nearest $0.1 \mathrm{~kg}$ while the participant wore light clothing with a digital weighing scale (Tanita Corporation, Tokyo, Japan) and checked daily with a known weight. WC was measured in a standing position using a non-stretchable measuring tape meter at the midpoint between the costal margin and iliac crests at the end of expiration to the nearest centimeter. $\mathrm{HC}$ was measured as the maximum circumference at the level of the greater trochanter (the widest portion of the hip) on both sides using a non-stretchable measuring tape meter. FBS was done with a simple finger prick using a digital glucometer. BP was measured three times in sitting position from the non-dominant arm at heart level using an aneroid sphygmomanometer (Yton sphygmomanometer, Italy) after the participant rested for $5 \mathrm{~min}$ before taking the measurement and $3 \mathrm{~min}$ before repeating the subsequent measurements, and the average was used for analysis. The resting 12 lead ECGs were obtained after a 10 -min rest, with $10 \mathrm{~mm} / \mathrm{mV}$ amplitude and paper speed of $25 \mathrm{~mm} / \mathrm{s}$ rates with standard lead positions in a supine position using YORK" 12 lead Electrocardiography (India). The recorded ECG was coded according to the Minnesota code and manually read by two cardiologists in a blinded manner having no information about the patients. The suggested procedure for electrocardiogram was followed in the reference to the standard manual for the Minnesota ECG criteria [22]. 


\section{Data processing and analysis}

The data were entered into Epi-data version 4.0.2. and exported to SPSS version 21 for analysis after checking for completeness. The exported data were explored to check outliers and missing values. Descriptive statistics like frequencies, percentages, mean, and standard deviations were carried out. Cross-tabulations and binary variable analyses were performed to select variables for multivariable analysis. The variables with a $p$ value $<0.25$ in the bivariable analysis were taken as candidates for multivariable analysis. Finally, multivariable logistic regression analysis was done using backward selection and the variables with a $p$ value of less than 0.05 were taken as statistically significant determinants of abnormality of ECG. The odds ratio with its 95\% CI was used to show the degree of association and estimation between the independent and the outcome variables.

\section{Results}

\section{Socio-demographic characteristics}

A total of 344 T2DM patients were interviewed and underwent electrocardiography giving a response rate of $100 \%$. The majority of 210 (61\%) of the respondents were males. The mean age of the respondents was $53.34 \pm 11.07$ years with a minimum age of 18 and a maximum of 80 years. More than half, 202 (58.7\%) of the respondents were in the age group of 51-70 years. Farmer respondents were 109 (31.7\%) while merchants and government employees accounted for 83 and 84 (24\%) respectively. More than half 199 (57.8\%) of the respondents were urban dwellers (Table 1 ).

\section{Behavioral measurements of the respondents}

The majority of the respondents, 333 (96.8\%) and 319 (92.7\%) were nonsmokers and non-alcohol users respectively. Most of the respondents 331 (96.2\%) were involved in physical activity less than $150 \mathrm{~min}$ of moderate or $75 \mathrm{~min}$ of vigorous physical activity per week (less than 600 metabolic equivalents of energy per week). Non-khat chewers accounted for 304 (88.4\%) of the respondents.

\section{Dietary factors of the respondents}

Most of the respondents 339 (98.5\%) were using fruits and vegetables below five servings per day. Five servings of fruit and vegetables per day (equivalent to $400 \mathrm{~g}$
Table 1 Sociodemographic characteristics of apparently healthy adult type 2 diabetes patients on follow-up at JMC May, 2019

\begin{tabular}{llll}
\hline Variable & Category & Frequency & Percent \\
\hline Age group in years & $<40$ & 46 & 13.4 \\
& $41-50$ & 70 & 20.3 \\
& $51-60$ & 111 & 32.3 \\
& $61-70$ & 91 & 26.4 \\
& $>70$ & 26 & 7.6 \\
Sex & Male & 210 & 61.0 \\
& Female & 134 & 39.0 \\
Occupational status & Farmer & 109 & 31.7 \\
& Daily laborer & 12 & 3.5 \\
& Merchant & 83 & 24.1 \\
& Government employee & 84 & 24.4 \\
& NGO/private & 31 & 9.0 \\
& Others & 7.3 \\
Elace of residency & Urban & 25 & 18.3 \\
& Rural & 63 & 39.5 \\
& Primary education & 136 & 21.5 \\
& Secondary education & 74 & 20.6 \\
& Tertiary education & 71 & 57.8 \\
& Nonal education & 199 & 42.2 \\
\hline
\end{tabular}

${ }^{a}$ Housewife, students, pensions, carpenter

Table 2 Distribution of anthropometric and blood pressure measurement of apparently healthy adult type 2 diabetes patients on follow-up at JMC May 2019

\begin{tabular}{llll}
\hline Variable & Category & Frequency & Percent \\
\hline Systolic BP & $<120 \mathrm{mmHg}$ & 106 & 30.8 \\
& $120-139 \mathrm{mmHg}$ & 238 & 69.2 \\
Diastolic BP & $<80 \mathrm{mmHg}$ & 161 & 46.8 \\
& $80-89 \mathrm{mmHg}$ & 183 & 53.2 \\
BMI category & Underweight & 27 & 7.8 \\
& Normal weight & 183 & 53.2 \\
& Over weight & 85 & 24.7 \\
& Obese & 49 & 14.2 \\
WC category & Normal & 126 & 36.6 \\
& Increased risk & 218 & 63.4 \\
WHR & Normal & 48 & 14.0 \\
& Increased risk & 296 & 86.0 \\
\hline
\end{tabular}

of fruits and vegetables) while solid oil users were 235 (68.3\%).

\section{Blood pressure measurements of the respondents}

An average systolic blood pressure (SBP) was $121.20 \pm 7.34 \mathrm{mmHg}$ while the average diastolic blood pressure (DBP) was $77.85 \pm 4.15 \mathrm{mmHg}$ (Table 2). 


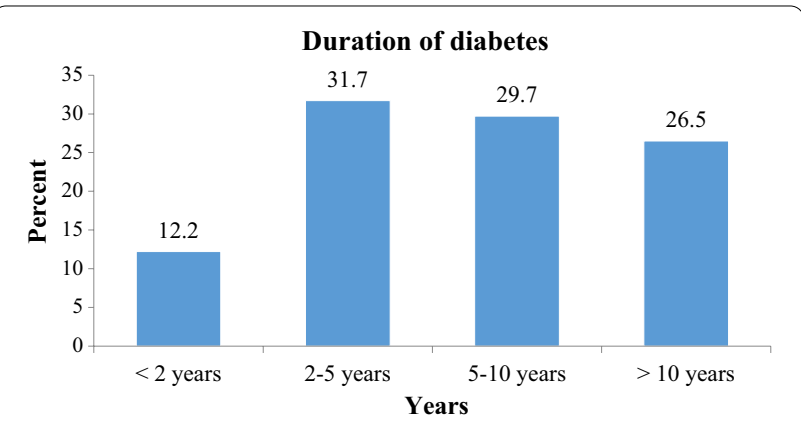

Fig. 1 Duration of diabetes of apparently healthy adult type 2 diabetes on follow up at JMC May 2019

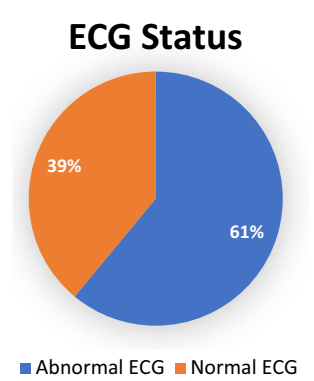

Fig. 2 Normal and abnormal ECG status of apparently healthy adult type 2 diabetes on follow up at JMC May 2019

\section{Duration of diabetes and blood glucose levels of the respondents}

The mean fasting blood glucose was $123.65 \pm 17.34 \mathrm{mg} / \mathrm{dl}$. From the total respondents, 210 (61\%) had a fasting blood sugar within a normal range whereas hyperglycemia and hypoglycemia were 123 $(35.8 \%)$ and $11(3.2 \%)$ respectively. The mean duration of diabetes was $7.31 \pm 4.54$ years with a minimum duration of 1 year and a maximum of 19 years. Most of the respondents 109 (31.7\%) and 102 (29.7\%) had a diabetes duration of $2-5$ and 5-10 years respectively (Fig. 1).

\section{ECG status of the respondents}

The majority of the respondents 209 (61\%) had at least one electrocardiogram abnormality (Fig. 2). ECG abnormality was 101 (29.4\%) among participants with abnormal body weight 21 (6.1\%) among underweight, 57 (16.6\%) among overweight, 23 (6.7\%) among obese), 136 (39.5\%) in high-risk WC, 69 (20.1\%) in DM duration $>10$ years, 158 (45.9\%) in Solid oil users and 109 (31.7) urban dwellers.

\section{Factors associated with ECG abnormalities} Binary and multivariable analysis

Variables like age category, educational status, occupation, place of residence, duration of DM, solid oil use, BMI category, WC category, SBP, and fasting blood sugar were associated with ECG abnormalities at a $p$ value of less than 0.25 . The finding of multivariable logistic regression indicated that educational status, duration of DM, solid oil, and BMI category were independently associated with ECG abnormality.

Diabetic patients who had no formal education were 3 times higher odds of more likely having abnormal ECG compared to those who had attended above secondary education ( $\mathrm{AOR}=3.07,95 \%, \mathrm{CI}=1.37-6.87)$. The odds of having ECG abnormality were 1.8 times higher among solid oil users compared to their counterparties $(\mathrm{AOR}=1.79,95 \%, \mathrm{CI}=1.07-2.98) . \quad \mathrm{ECG}$ abnormality also showed association with participants with a BMI of $\geq 25 \mathrm{~kg} / \mathrm{m}^{2}$. Patients with $\mathrm{BMI} \geq 25 \mathrm{~kg} /$ $\mathrm{m}^{2}$ were 2.7 times odds more likely to develop ECG abnormality compared to normal weighted diabetic patients $(\mathrm{AOR}=2.74,95 \%, \mathrm{CI}=1.67-4.50)$. The duration of DM had also an association with ECG abnormalities. Those who had a duration of diabetes greater than 10 years were 3 times the odds more likely to develop ECG abnormality compared with patients with a duration of fewer than two years $(\mathrm{AOR}=3.36,95 \%$, CI $=1.46-7.71$ ) (Table 3 ).

\section{Discussion}

Two hundred nine (61\%) of the respondents had at least one type of ECG abnormality. This finding is comparable with a study conducted in the United States (60\%) [26]. But, it is lower than the study done in Uganda (67.8\%) [27]. On the other hand, the present finding was higher than the studies conducted in Slovakia (53.7\%) [28], India (26\%) [29], and Sudan (23\%) [30]. These differences may be due to the difference in the socio-economic, health care system, other co-morbidities, study design, selection criteria, the presence or absence of other risk factors, environmental and genetic variations.

Lack of formal education was one of the predictors of ECG abnormality among T2DM patients. This finding was supported by the study conducted in Sweden [31], Iran [32], Malaysia [33], and Japan [34] that revealed higher risks of CVDs among diabetic patients with low educational status. A study conducted in 20 developing countries showed that CVDs were more common among those with low levels of education [35]. The lack of education affects individuals' health literacy. Inadequate health literacy might increase the risk of diabetic cardiac impairment [36]. 
Table 3 Bivariable and multivariable analysis of factors associated with ECG abnormalities among apparently healthy adult type 2 diabetes on follow-up at JMC May 2019

\begin{tabular}{|c|c|c|c|c|c|}
\hline \multirow[t]{2}{*}{ Variable } & \multirow[t]{2}{*}{ Category } & \multicolumn{2}{|c|}{ ECG abnormality } & \multirow[t]{2}{*}{ COR $(95 \% \mathrm{Cl})$} & \multirow[t]{2}{*}{ AOR $(95 \% \mathrm{Cl})$} \\
\hline & & No (\%) & Yes (\%) & & \\
\hline \multirow[t]{5}{*}{ Age group (yrs.) } & $<40$ & $23(6.7)$ & $23(6.7)$ & 1 & 1 \\
\hline & $40-50$ & $31(9.0)$ & $39(11.3)$ & $1.26[.60-2.65]$ & $1.03[.45-2.38]$ \\
\hline & $51-60$ & 40 (11.6) & 71 (20.6) & $1.78[.89-3.56]$ & $1.42[.64-3.15]$ \\
\hline & $61-70$ & $35(10.2)$ & $56(16.3)$ & $1.60[.78-3.27]$ & $1.14[.50-2.61]$ \\
\hline & $>70$ & $6(1.7)$ & $20(5.8)$ & $3.33[1.13-9.82]^{*}$ & $1.90[.58-6.21]$ \\
\hline \multirow[t]{4}{*}{ Educational status } & No formal education & $14(4.1)$ & $49(14.2)$ & $3.81[1.79-8.10]^{*}$ & $3.07[1.37-6.87]^{*}$ \\
\hline & Primary education & $51(14.5)$ & $85(24.7)$ & $1.81[1.02-3.24]^{*}$ & $1.79[.96-3.31]$ \\
\hline & Secondary education & $33(9.6)$ & $41(11.9)$ & $1.35[.70-2.60]$ & $1.65[.82-3.35]$ \\
\hline & Tertiary education & $37(10.8)$ & $34(9.9)$ & 1 & 1 \\
\hline \multirow[t]{6}{*}{ Occupation } & Farmer & $34(9.9)$ & $75(21.8)$ & 1 & 1 \\
\hline & Daily labor & $5(1.5)$ & $7(2.0)$ & $.64[.19-2.14]$ & $.77[.18-3.23]$ \\
\hline & Merchant & $36(10.5)$ & $47(13.7)$ & $.59[.33-1.07]$ & $1.14[.46-2.81]$ \\
\hline & Government employ & $39(11.3)$ & $45(13.1)$ & $.52[.29-.94]^{*}$ & $.1 .54[.57-4.19]$ \\
\hline & NGO/private & $14(4.1)$ & $17(4.9)$ & $.55[.24-1.24]$ & $1.72[.61-4.85]$ \\
\hline & Other & $7(2.0)$ & $18(5.2)$ & $1.17[.45-3.05]$ & $1.42[.42-4.74]$ \\
\hline \multirow[t]{2}{*}{ Place of residency } & Urban & $90(26.2)$ & $109(31.7)$ & $.55[.35-.85]^{*}$ & $.83[.49-1.44]$ \\
\hline & Rural & $45(13.1)$ & $100(29.1)$ & 1 & 1 \\
\hline \multirow[t]{2}{*}{ Solid oil use } & Yes & $77(22.4)$ & $158(45.9)$ & $2.33[1.47-3.71]^{* *}$ & $1.79[1.07-2.98]^{*}$ \\
\hline & No & $58(16.9)$ & $51(14.8)$ & 1 & 1 \\
\hline \multirow[t]{4}{*}{ Duration of DM } & $<2$ years & $20(5.8)$ & $22(6.4)$ & 1 & 1 \\
\hline & $2-5$ years & $41(11.9)$ & $68(19.8)$ & $1.51[.74-3.09]$ & $1.79[.83-3.88]$ \\
\hline & $5-10$ years & $52(15.1)$ & $50(14.5)$ & $.87[.43-1.80]$ & $1.02[.47-2.21]$ \\
\hline & $>10$ years & $22(6.4)$ & $69(20.1)$ & $2.85[1.32-6.17]^{*}$ & $3.36[1.46-7.71]^{*}$ \\
\hline \multirow[t]{2}{*}{ Fasting BGL } & Normal fasting BGL & $91(26.5)$ & $120(34.9)$ & 1 & 1 \\
\hline & Abnormal fasting BGL & $44(12.8)$ & 89 (25.9) & $1.53[.98-2.41]$ & $1.43[.86-2.37]$ \\
\hline \multirow[t]{2}{*}{ Average SBP } & Normal BP & $36(10.5)$ & $70(20.3)$ & 1 & 1 \\
\hline & Abnormal BP & $99(28.8)$ & $139(40.4)$ & $.72[.45-1.16]$ & $.59[.35-1.01]$ \\
\hline \multirow[t]{2}{*}{ WC category } & Normal & $53(15.4)$ & $73(21.2)$ & 1 & 1 \\
\hline & Risk & $82(23.8)$ & $136(39.5)$ & $1.20[.77-1.88]$ & 1.19 [.70-2.03] \\
\hline \multirow[t]{2}{*}{ BMI category } & Normal weight & $90(26.2)$ & $94(27.3)$ & 1 & 1 \\
\hline & Abnormal weight & $45(13.1)$ & $115(33.4)$ & $2.43[1.55-3.82]^{* *}$ & $2.74[1.67-4.50]^{* *}$ \\
\hline
\end{tabular}

The bold is used to help the reader to easily get the variables that are significantly associated with ECG abnormality either in binary or multiple logistic regression ${ }^{*} p<0.05 ;{ }^{* *} p<0.001$

The use of solid oil was one of the predictors of electrocardiographic abnormalities among T2DM patients in this study. High saturated fatty acid causes cardiometabolic dysfunction and poor glycemic control [37]. The cell membrane fatty acid change has a direct and indirect effect on the electrophysiological property [38]. This finding was in harmony with studies conducted in Europe [39] and Israel [40] that showed the substitution of carbohydrates with saturated fatty acid increases the risk of CVDs and as dietary modification reduces CVDs the risks among T2DM respectively. Saturated fatty acid use reduces endothelial function and insulin sensitivity being a risk of CVDs [41].

This study also revealed that increased body weight was also associated with ECG abnormality. An increment in body mass index greater than $25 \mathrm{~kg} / \mathrm{m}^{2}$ was strongly associated with ECG abnormality. This finding was supported by the study conducted in Turkey on ECG parameter changes in overweight individuals compared with the normoweight [42]. Obesity alters the morphology and electrophysiology of myocardial cells and increases CVDs risks shifts the cardiac axis leftward [43] and may increase the risk of atherogenesis [44]. The meta-analysis 
findings revealed that excess weight is associated with CVDs mortality [45]. Obesity may also cause abnormal myocardial perfusion among T2DM patients [46].

The duration of diabetes greater than ten years was also among the factors that affect ECG patterns. This finding was supported by the study conducted in India showed the duration of diabetes mellitus 5-10 years had ECG changes [29]. Another survey conducted in Denmark also showed heart failure was diagnosed $37.4 \%$ after 10 years or more in type 2 diabetes [47]. Similarly, the study conducted in Sweden among diabetic patients revealed a longer duration of diabetes increases the risk of CVDs [48].

\section{Limitation of the study}

Biochemical measurements like lipid profile and serum electrolytes were not done due to budget shortage.

\section{Conclusion and recommendation}

In this study, the majority (3/5th) of the participant had ECG abnormality. Not attending formal education, longer duration of $\mathrm{DM} \geq 10$ years, solid oil use, and increased $\mathrm{BMI} \geq 25 \mathrm{~kg} / \mathrm{m}^{2}$ were independent predictors of ECG abnormality. Integrating ECG screening in routine diabetic management helps to better manage the impact of T2DM on the cardiovascular system.

\begin{abstract}
Abbreviations
AOR: Adjusted odds ratio; BMI: Body mass index; BP: Blood pressure; COR: Crude odd ratio; CVDs: Cardiovascular diseases; DM: Diabetes mellitus; ECG: Electrocardiogram; FBS: Fasting blood sugar; JMC: Jimma Medical Center; T2DM: Type 2 diabetes mellitus; WC: Waist circumference; WHO: World health organization; WHR: Waist to hip ratio.
\end{abstract}

\section{Supplementary Information}

The online version contains supplementary material available at https://doi. org/10.1186/s12872-021-02110-6.

Additional file 1. The measurement procedures of blood pressure, anthropometry, fasting blood glucose level, and recording of electrocardiography.

Additional file 2. Patient's information sheets.

\section{Acknowledgements}

I want to acknowledge my data collectors, study participants, and Jimma University as well as Jimma Medical Center.

\section{Authors' contributions}

DA was involved in conceiving the idea, study design, and managing the overall progress of the study. All authors have participated in data analysis and interpretation. DA and ST drafted the first manuscript and then edited it by $M B, W R$, and GD. All authors read and approved the final version of the manuscript
Funding

This research was funded by the institute of health sciences, Jimma University.

\section{Availability of data and materials}

The datasets used and analyzed during the current study are available from the corresponding author on reasonable request.

\section{Declarations}

Ethical approval and consent to participate

This study was approved by the school of graduate studies of Jimma University and ethical clearance was obtained from the ethical review board of Jimma University, Institute of Health (IHRPG1/519/2019). It was confirmed that the study met the ethical and scientific standards outlined in national and international guidelines. Then it was permitted and supervised by the Department of internal medicine. All the study participants were informed about the purpose of the study, their right to refuse, assured confidentiality, and informed written consent was obtained before the interview and recording of ECG. The measurements of blood pressure [24], anthropometry (weight, height, waist circumference, and hip circumferences) [23], fasting blood glucose level [25], and recording of electrocardiography [22] were made according to the respective guidelines.

\section{Consent for publication}

Not applicable.

\section{Competing interest}

All authors declare that they have no competing interest.

\section{Author details}

${ }^{1}$ Department of Biomedical Sciences, Physiology Unit, College of Medical Sciences, Institute of Health, Jimma University, Jimma, Ethiopia. ${ }^{2}$ Jimma Medical Center, Department of Internal Medicine, College of Medical Sciences, Institute of Health, Jimma University, Jimma, Ethiopia.

Received: 21 October 2020 Accepted: 7 June 2021

Published online: 24 June 2021

\section{References}

1. American Diabetic Association. Diabetes care in the hospital: standards of medical care in diabetesd 2018. Diabetes Care. 2018;41:S144-51.

2. Fox CS, Golden SH, Anderson C, Bray GA, Burke LE, De Boer IH, et al. Update on prevention of cardiovascular disease in adults with type 2 diabetes mellitus in light of recent evidence: a scientific statement from the American Heart Association and the American diabetes association. Diabetes Care. 2015;38:1777-803.

3. Glezeva N, Chisale M, Mcdonald K, Ledwidge M, Gallagher J, Watson CJ. Diabetes and complications of the heart in Sub-Saharan Africa: an urgent need for improved awareness, diagnostics and management. Diabetes Res Clin Pract. 2018;137:10-9.

4. Cho NH, Shaw JE, Karuranga S, Huang Y, da Rocha Fernandes JD, Ohlrogge AW, et al. IDF diabetes atlas: global estimates of diabetes prevalence for 2017 and projections for 2045. Diabetes Res Clin Pract. 2018;138:271-81.

5. Mohan V, Cooper ME, Matthews DR, Khunti K. The standard of care in type 2 diabetes: re-evaluating the treatment paradigm. Diabetes Ther. 2019:10:1-13.

6. Peer N, Kengne AP, Motala AA, Mbanya JC. Diabetes in the Africa region: an update. Diabetes Res Clin Pract. 2014;103:197-205.

7. Adebamowo SN, Tekola-ayele F, Adeyemo AA, Rotimi CN. Genomics of cardiometabolic disorders in Sub-Saharan Africa. PHG. 2017;20:9-26.

8. Khandoker AH, Al-Angari HM, Khalaf K, Lee S, Almahmeed W, Al Safar HS, et al. Association of diabetes related complications with heart rate variability among a diabetic population in the UAE. PLoS ONE. 2017;12:4-10.

9. International Diabetes Federation. Diabetes and cardiovascular disease. Brussels: 2016.

10. World Health Organization. Global Report on Diabetes. Vol. 978, Isbn. 2016. 
11. Shiferaw F, Letebo M, Misganaw A, Feleke Y, Gelibo T. Non-communicable diseases in Ethiopia: disease burden, gaps in health care delivery and strategic directions. Ethiop J Heal Dev. 2018;32:1-12.

12. Leon BM, Maddox TM. Diabetes and cardiovascular disease: epidemiology, biological mechanisms, treatment recommendations and future research. World J Diabetes. 2015;6:1246-58.

13. Grisanti LA. Diabetes and arrhythmias: pathophysiology, mechanisms and therapeutic outcomes. Front Physiol. 2018;9:1-15.

14. Brunetti A, Indolfi C. Type 2 diabetes mellitus and cardiovascular disease: genetic and epigenetic links. Endocrinology. 2018;9:1-13.

15. Fox CS, Golden SH, Anderson C, Bray GA, Burke LE, De BIH, et al. Prevention of cardiovascular disease in adults with type 2 diabetes mellitus in light of recent evidence: a scientific statement from the American Heart Association and the American Diabetes Association. Circulation. 2015;132:691-718.

16. Rajni R, Kaur I. Electrocardiogram signal analysis_an overview. Int J Comput Appl. 2013;84:22-5

17. Perez MV, Dewey FE, Tan SY, Myers J, Ph D, Froelicher VF. Added value of a resting ECG neural network that predicts cardiovascular mortality. Ann Noninvasive Electrocardiol. 2009;14:26-34.

18. Tavares CAF, Wajchjenberg BL, Rochitte C, Lerario AC. Screening for asymptomatic coronary artery disease in patients with type 2 diabetes mellitus. Endocrinol Metab. 2016;60:143-51.

19. Soliman EZ, Backlund JYC, Bebu I, Orchard TJ, Zinman B, Lachin JM. Electrocardiographic abnormalities and cardiovascular disease risk in type 1 diabetes: the epidemiology of diabetes interventions and complications (EDIC) study. Diabetes Care. 2017;40(6):793-9.

20. Schernthaner G, Lotan C, Trendafilova EB, Ceponis J, Clodi M, Ducena K, et al. Unrecognised cardiovascular disease in type 2 diabetes: is it time to act earlier? Cardiovasc Diabetol. 2018;17:4-9.

21. World Health Organization: The WHO STEPwise approach to Surveillance of noncommunicable diseases ( STEPS ). World Health Organization. 2003;1-42

22. Prineas RJ, Crow RS, Zhang Z-M. The Minnesota Code Manual of Electrocardiographic Findings. second. The Minnesota Code Manual of Electrocardiographic Findings. New York: springer; 2010. 1-338 p.

23. World Health Organization. Waist Circumference and Waist-Hip Ratio Report of a WHO Expert Consultation. 2008.

24. O'Brien E, Asmar R, Beilin L, Imai Y, Mallion JM, Mancia G, et al. European Society of Hypertension recommendations for conventional, ambulatory and home blood pressure measurement. J Hypertens. 2003;21:821-48.

25. Center C and TR. Standard Operating Procedures 1. 2012.

26. Sellers MB, Divers J, Lu L, Xu J, Smith SC, Bowden DW, et al. Prevalence and determinants of electrocardiographic abnormalities in African Americans with type 2 diabetes. J Epidemiol Glob Health. 2014;4:289-96.

27. Muddu M, Mutebi E, Mondo C. Prevalence, types and factors associated with echocardiographic abnormalities among newly diagnosed diabetic patients at Mulago Hospital. Afr Health Sci. 2016;16:183-93.

28. Gaspar L, Murin J, Oravec S, Bulas J, Caprnda M. Holter ECG fi ndings in diabetics with medial arterial calci fi cation. Bratisl Med J. 2019;120:676-9.

29. Gupta S, Gupta RK, Kulshrestha M, Chaudhary RR. Evaluation of ECG abnormalities in patients with asymptomatic type 2 diabetes mellitus. J Clin Diagnostic Res. 2017;11:OC39-41.

30. Ishag M. Pattern of ECG abnormality in type 2 diabetic patients in Shendi locality-Sudan. IJRDO-J Heal Sci Nurs. 2016;1:7-14.

31. Rawshani A, Svensson A-M, Zethelius B, Eliasson B, Rosengren A, Gudbjörnsdottir S. Association between socioeconomic status and mortality, cardiovascular disease, and cancer in patients with type 2 diabetes. JAMA Intern Med. 2016;176:1146-54.

32. Madmoli M, Eilami O, Rezaie K, Aliabad MA, Moslemirad O. Diabetes and the risk of suffering cardiovascular diseases. Int J Ecosyst Ecol Sci. 2018:8:649-56.
33. Su TT, Amiri M, Hairi FM, Thangiah N, Bulgiba A, Majid HA. Prediction of cardiovascular disease risk among low-income Urban Dwellers in Metropolitan Kuala Lumpur. Malays Biomed Res Int. 2015;2015:1-8.

34. Okuda N, Nishi N, Kadota A, Okamura T, Ueshima H. Socioeconomic status and knowledge of cardiovascular risk factors. J Epidemiol. 2018;28:46-52.

35. Rosengren A, Smyth A, Rangarajan S, Ramasundarahettige C, Bangdiwala $\mathrm{SI}$, Alhabib KF, et al. Socioeconomic status and risk of cardiovascular disease in the prospective Urban Rural Epidemiologic (PURE) study. Lancet Glob Heal. 2019;7:748-60

36. van Schaik TM, Jørstad HT, Twickler TB, Peters RJG, Tijssen JPG, Essink-Bot $\mathrm{ML}$, et al. Cardiovascular disease risk and secondary prevention of cardiovascular disease among patients with low health literacy. Netherlands Hear J. 2017;25(7-8):446-54.

37. Apaijai N, Arinno A, Palee S, Pratchayasakul W, Kerdphoo S, Jaiwongkam T, et al. High-saturated fat high-sugar diet accelerates left-ventricular dysfunction faster than high-saturated fat diet alone via increasing oxidative stress and apoptosis in obese-insulin resistant rats. Mol Nutr Food Res. 2019;63:1-12.

38. Coronel R. Pharmacology and therapeutics the pro- or antiarrhythmic actions of polyunsaturated fatty acids and of cholesterol. Pharmacol Ther. 2017;176:40-7

39. Freisling $H$, Overvad K, Boeing H, Masala G, Panico S, Tumino R, et al. The association of substituting carbohydrates with total fat and different types of fatty acids with mortality and weight change among diabetes patients. Clin Nutr. 2016;35:1096-102.

40. Elhayany A, Lustman A, Abel R, Vinker S. A low carbohydrate Mediterranean diet improves cardiovascular risk factors and diabetes control among prospective randomized intervention study. Diabetes, Obes Metab. 2010;12:204-9.

41. Lane-cordova AD, Witmer JR, Dubishar K, Dubose LE, Chenard CA, Siefers $\mathrm{KJ}$, et al. High trans but not saturated fat beverage causes an acute reduction in postprandial vascular endothelial function but not arterial stiffness in humans. Vasc Med. 2016;21:429-36.

42. Kuzu F. Relation of homeostasis model of insulin resistance and body mass index with cardiac repolarization inhomogeneity in overweight and obese patients. Int Med J. 2018;07:1

43. Hussain G, Farooque I. Effect of obesity on electrocardiographic parameters of ventricular repolarization in healthy adults. J Evid Based Med Healthc. 2017:4:5915-20.

44. Varun S, Jain HR, Singh GS, Parekh S, Shetty S. Cardiovascular and electrocardiography changes in obese individuals at rest and during stress test. Int J Sci Study. 2017;5(3):172-8.

45. Chen H, Deng Y, Shunhui L. Relation of body mass index categories with risk of sudden cardiac death. Int Heart J. 2019;60(3):624-30.

46. Dippe T, Cunha CL, Cerci RJ, Stier AL, Vítola JV. Study of myocardial perfusion in obese individuals without known ischemic heart disease. Arq Bras Cardiol. 2018;112:121-8.

47. Rungby J, Schou M, Warrer P, Ytte L, Andersen GS. Prevalence of cardiovascular disease and evaluation of standard of care in type 2 diabetes: A nationwide study in primary care. Cardiovasc Endocrinol. 2017;6:145-51.

48. Eryd SA, Svensson A, Franz S, Eliasson B, Nilsson PM. Epidemiology risk of future microvascular and macrovascular disease in people with type 1 diabetes of very long duration: a national study with 10-year follow-up. DIABETICMedicine 2016:34:411-8.

\section{Publisher's Note}

Springer Nature remains neutral with regard to jurisdictional claims in published maps and institutional affiliations. 